\title{
Efficiency of Tamsulosin after Shockwave Lithotripsy for the Treatment of Lower Ureteric Stone: Alkaramah Teaching Hospital Experience, Iraq
}

\author{
Yarub Fadhil Hussein'1, Basim Jasim Abdulhussein², Abdulsalam Hatem Nawar'1, \\ Redhwan Ahmed Al-Naggar ${ }^{3}$ \\ ${ }^{1}$ Department of Urology, Al Karamaha Teaching Hospital, Karkh, Baghdad, Iraq \\ ${ }^{2}$ Department of Surgery, Al Karamaha Teaching Hospital, Karkh, Baghdad, Iraq \\ ${ }^{3}$ Population Health and Preventive Medicine, Faculty of Medicine, Universiti Teknologi MARA, Shah Alam, \\ Malaysia \\ Email: yarubfadhil@gmail.com
}

Received 29 April 2015; accepted 17 May 2015; published 20 May 2015

Copyright (C 2015 by authors and Scientific Research Publishing Inc.

This work is licensed under the Creative Commons Attribution International License (CC BY).

http://creativecommons.org/licenses/by/4.0/

c) (i) Open Access

\begin{abstract}
Background: Stone disease is a wide health problem; certain drugs have been used as supplement with ESWL for the treatment of symptomatic uncomplicated lower ureteric stone like Nefidipine, Alfuzosin and Tamsulosin. The purpose of this study is to evaluate the efficacy of Tamsulosin for the treatment of lower ureteric stone of 5 - 10 mm diameter after ESWL. Methods: A total of 105 patients with lower ureteric stone of less than $10 \mathrm{~mm}$ diameters were divided into two groups. Group 1 including 48 patients received $0.4 \mathrm{mg}$ Tamsulosin and diclofenac sodium analgesia as needed immediately after ESWL and continued until stone expulsion was confirmed up to maximum of 30 days. Group 2 including 47 patients was given diclofenac sodium only as needed after ESWL. Result: 46 of 49 patients in group 1 and 44 of 48 patients in group 2 ultimately passed stones. The number of ESWL sessions was $1.4 \pm 0.6$ in group $1 \& 1.42 \pm 0.75$ in group 2 . There were 10 patients who needed analgesia after ESWL in group 1 and 17 patients in group 2. Visual analogue scale pain severity score was $5.32 \pm 1.23$ and $6.41 \pm 1.26$ in group 1 and 2 , respectively. The time to stone expulsion in group 1 and 2 was $8 \pm 5.4$ days and $12 \pm 10.3$ days, respectively. No significant complications or side effects occurred. Conclusion: The use of Tamsulosin in combination with ESWL in patients with lower ureteric stone of $5 \mathbf{- 1 0 ~} \mathbf{~ m m}$ was effective for reducing the time to stone expulsion, decreasing need for analgesia, and facilitating stone passage without significant improvement in stone free rate.
\end{abstract}




\section{Keywords}

\section{Tamsulosin, Shockwave, Lithotripsy, Ureteric Stone, Iraq}

\section{Introduction}

Urolithiasis is a health problem worldwide. It is believed that conservative treatment for ureteric stone should be applied first [1], including analgesia and oral hydration; however the success rate of conservative treatment depends mainly on the size and location of the stone. If conservative treatment is unsuccessful shock wave, lithotripsy or ureteroscopy can be utilized [2]. Ureteral stone accounts for $20 \%$ of urolithiasis and $70 \%$ of it is in the lower third of the ureter. For distal ureteric stone of 5 - $10 \mathrm{~mm}$ diameter, spontaneous expulsion occurs in $25 \%$ $53 \%$ of cases [3].

Although ESWL is an effective noninvasive outpatient treatment modality, the success rate of ESWL is not as high as that of ureteroscopic lithotripsy [4]. Furthermore renal colic is caused by steinstrasse after ESWL and the prolonged time of treatment is problematic. To prevent these complications, ESWL combines with the administration of an alpha adrenergic receptor (AR) antagonist such as Tamsulosin. Alpha 1 AR decreases the tension of ureteral smooth muscles, peristaltic frequency and amplitude of the ureter [5]. As a result the increased intra ureteral pressure gradient created around the stone facilitates its expulsion by urinary flow.

The pharmacological selectivity and potency for the various AR subtypes differ from those of other alpha AR such as alfuzosin, doxazosin and terazosin, and the expression level of each alpha 1 AR subtype depends on the location within the ureter [6]. Tamsulosin is the most commonly used alpha blocker for the medical treatment of ureteric stone because of its excellent tolerability, the lack of need for dose titration and its uroselectivity for alpha 1a and alpha 1d resulting in relaxation of the smooth muscles of the lower ureter, facilitation of stone passage and relieving of pain [7]. The aim of this prospective study was to evaluate the efficacy of Tamsulosin after ESWL in treatment of lower ureteric stone, facilitation of passage of stone and reduction of attack of pain after ESWL.

\section{Methods}

Patients presenting at the emergency department or urologic clinic at Alkaramah teaching hospital in Iraq with acute renal colic were evaluated for study participating in prospective manner between May 2014 \& February 2015. Distal ureteral stones were diagnosed on the basis of KUB, ultrasound and helical CT when necessary. The lower ureter was defined as the segment from the lower boarder of sacroiliac joint to the vesicoureteric junction. Additionally, the patients underwent series of measurements including history, physical examination, CBC, GUE, serum creatinine and blood urea.

Inclusion criteria were: patients more than 15 years of age and single unilateral ureteric stone of 5 - $10 \mathrm{~mm}$ diameter. Patients were excluded if they need any of the following criteria: Age less than 15 years, pregnant or lactating woman, multiple stones, stone more than $10 \mathrm{~mm}$ diameter, bilateral ureteric stone, moderate or severe hydronephrosis, bleeding tendency, history of pelvic surgery, severe UTI, intolerable pain, solitary kidney, renal impairment, Aortic or renal artery aneurism or contraindication to alpha antagonist treatment. All patients were treated with Karl Storz Lithotripter HMIII in outpatient setting without ant anesthesia with energy of 8 \& frequency $2 \mathrm{~Hz}$. Intra muscular or intra venous administration of analgesia was used for pain control during ESWEL.

After ESWL all patients were divided into 2 groups. Group 1received diclofenac sodium only IM as needed while group 2 received Tamsulosin $0.4 \mathrm{mg}$ once daily and diclofenac sodium $100 \mathrm{mg}$ IM as needed. The assignment of each treatment modality was randomized using simple randomization method where the patients were blinded. Administration of drugs started immediately after ESWL and continued after stone expulsion was confirmed with KUB up to 30 days after the procedure. Follow up visit weekly done. If the ureteral stone remained and was larger than $5 \mathrm{~mm}$ in diameter at the follow up visit additional ESWEL was performed. Efficacy of Tamsulosin was assessed in term of the stone free rate, time of stone expulsion, and severity of pain compared with analgesic group only. After all study steps the data including stone size, stone free rate, time of stone expulsion, visual analog scale (VAS) score of pain severity, and adverse effects were analyzed. The VAS was 
scored. For pain intensity, the scale is most commonly anchored by "no pain" (score of 0) and "pain as bad as it could be" or "worst imaginable pain" score of 100 [8].

We estimated that 104 patient is sufficient to detect a difference of 4 days as reduction in the time of expulsion of the stone between the two groups. Descriptive statistics were produced for all variables under study. Independent samples $t$ test was used to test the significance of mean difference between two groups while chi square test was used with categorical data. Significance level was set at 0.05 .

\section{Results}

A total of 105 patients were enrolled in the study, and 95 patients completed the study, 6 patients in group 1 and 4 patients in group 2 dropped out owing to discontinuation of treatment. Table 1 shows the distribution of main characteristic of the study sample. It is observable that males were more represented than female. More than half of the stones were in the right distal ureter.

Age, gender, size and location of the ureteric stone didn't differ significantly between the two groups. The mean size of the ureteric stone in group 1 was 7.3 (1.65) $\mathrm{mm}$ and almost equal size of group 2 with 7.2 (1.73) $\mathrm{mm}$. Exactly 44 out of 47 patients in group 1 and 45 out of 48 patient from group 2 were stone free by the end of the study. The stone free rate was not significantly different between the two groups $(\mathrm{p}=0.217)$. The number of ESWL sessions were $1.51(0.55)$ and $1.43(0.55)$ in group $1 \& 2$ respectively $(\mathrm{p}=0.76)$. The mean time of stone expulsion was significantly lower among group 2 with mean of 8.5 (5.6) days compared to 17.6 (8.8) days in group $2(\mathrm{p}=0.041)$.Similarly the VAS mean was significantly lower among group 2 . Moreover, rate of renal colic was lower among group 2 than group $1(\mathrm{p}=0.012)$. No severe complications developed in either group, mild muscle spasm occur in 1 patient in group 1 and retrograde ejaculation also encountered in 3 patients in group 2. No significant complications or side effects occur (see Table 2).

\section{Discussion}

The alpha 1 AR antagonist has been shown to be more effective than Nefidipine, steroid and other nonsteroidal anti-inflammatory drug in aiding the expulsion of ureteric stones. The expression of alpha 1 AR is significantly higher in the distal ureter than in the proximal and mid ureter. The alpha 1a and alpha 1d AR subtypes are the most common subtype throughout the human ureter. The alpha $1 \mathrm{~d}$ AR subtype is the most common in the mid $\&$ distal ureter.

Where is the alpha 1a \& alpha $1 \mathrm{~d}$ AR subtypes are similarly prevalent in the proximal ureter. Tamsulosin has selective and high affinity for alpha 1a and alpha 1d subtypes and the efficacy of Tamsulosin with ESWL have been demonstrated in several studies. Kupeli et al. [7] evaluated the role of Tamsulosin in medical expulsive therapy (Met) of lower ureteric stones. In that study the success rate of the Tamsulosin group with or with-

\section{Table 1. Descriptive statistics of the sample.}

\begin{tabular}{|c|c|c|c|}
\hline & & $\mathbf{n}$ & $\%$ \\
\hline \multirow{2}{*}{ Gender } & Male & 78 & 82.105 \\
\hline & Female & 17 & 17.895 \\
\hline \multirow{2}{*}{ Site } & right & 42 & 44.211 \\
\hline & left & 53 & 55.789 \\
\hline \multirow{2}{*}{ Ureteric colic } & No & 19 & 20 \\
\hline & Yes & 76 & 80 \\
\hline \multirow{2}{*}{ Gross haematuria } & No & 92 & 96.842 \\
\hline & Yes & 3 & 3.1579 \\
\hline \multirow{2}{*}{ Microscopic haematuria } & No & 52 & 54.737 \\
\hline & Yes & 43 & 45.263 \\
\hline \multirow{2}{*}{ UIT } & No & 85 & 89.474 \\
\hline & Yes & 10 & 10.526 \\
\hline Age mean (SD) & & $42(5)$ & \\
\hline
\end{tabular}


Table 2. Distribution of treatment modality by selected variables.

\begin{tabular}{|c|c|c|c|c|}
\hline & & Dilco & Diclo + Tams & $\mathrm{p}$ \\
\hline \multirow{2}{*}{ Gender } & Male & 33 & 45 & \multirow{2}{*}{0.853} \\
\hline & Female & 7 & 10 & \\
\hline \multirow{2}{*}{ Site } & Right & 25 & 27 & \multirow{2}{*}{0.649} \\
\hline & Left & 22 & 21 & \\
\hline \multirow[t]{2}{*}{ Renal colic } & No & 31 & 51 & \multirow{2}{*}{0.012} \\
\hline & Yes & 9 & 4 & \\
\hline \multirow{2}{*}{ Stone free } & No & 3 & 3 & \multirow{2}{*}{0.217} \\
\hline & Yes & 44 & 45 & \\
\hline Mean age & & 42.1 & 42.3 & 0.812 \\
\hline Size (mm) & & $7.3(1.65)$ & $7.2(1.73)$ & 0.763 \\
\hline Time to free (d) & & $17.6(8.8)$ & $8.5(5.6)$ & 0.041 \\
\hline Visual Analogue scale of pain & & $6.44(1.33)$ & $5.31(1.32)$ & 0.036 \\
\hline Average no of sessions & & $1.51(0.55)$ & $1.43(0.55)$ & 0.766 \\
\hline Average energy (J) & & 213 & 208 & 0.472 \\
\hline Average shock per case & & 5.6 & 5.53 & 0.859 \\
\hline
\end{tabular}

out ESWL was higher than that of the control group. Kobayashi et al. [9] evaluated the efficacy of low dose Tamsulosin $0.2 \mathrm{mg}$ combined with ESWL in that study the stone free rate didn't differ but the time of stone expulsion was shorter in the Tamsulosin group than in the control group (15.7 days in the Tamsulosin vs 35.5 days in the control group). In the present study the stone free rate after ESWL in both groups was greater than $90 \%$ with no significant difference between the groups but the time of stone expulsion was significantly shorter in Tamsulosin group.

The stone free rate and the timer of stone expulsion were better than previous reports describing adjunctive (met) combined with ESWL [10]-[13]. Our inclusion criteria of small ureteric stone and the additional of ESWL might explain the high stone free rate in the study. In our study the means of (VAS) score after ESWL were (5.31) \& (6.44) for the Tamsulosin group and the control group; respectively.

The rate of renal colic episode after ESWL were (29\%) \& (7\%) among group 1 and group 2 respectively. The subjective pain scale \& the rate of renal colic episode was less in the Tamsulosin group than the control group. Yilmaz et al. [6] compared the efficacies of Tamsulosin, Terazosin and Doxazosin in treating patients with lower ureteric stone less than $10 \mathrm{~mm}$ diameter. In that study these 3 alpha AR antagonist showed better stone free rate and decrease pain episodes $\&$ analgesic used compared with the controlled group.

In study comparing the efficacy of Alphazosin and Tamsulosin in treating patients with lower ureter stones both AR antagonists showed high success rate of stone expulsion compared with control group. Minorside effects including headache, dizziness and hypotension occurred at similar rate in both groups but $4.9 \%$ to $6.9 \%$ of patients in the Tamsulosin group experienced retrograde ejaculation which was not seen in the other groups (20, 21). In the present study the stone expulsion rate and the incidence of minor side effects were similar to the other published studies. Tamsulosin has higher selectivity for alpha 1 A and alpha 1 D AR than do other alpha blockers (23).

The strong affinity of Tamsulosin for these receptors lead to high success rate of (met) \& may explain why these agents cause retrograde ejaculation in young male patients [14]. The incidence of ejaculatory disorder such as retrograde ejaculation is reported to be $0 \%$ to $0.3 \%$ in patients receiving Alphazosin [15] [16], where is an ejaculatory disorder occur in 6\% - 18\% of patient receiving Tamsulosin [17] [18]. The affinity of Tamsulosin for alpha 1a AR play an important role in the contraction of the VAS difference and seminal vesicle [19] [20] and may be one of the reasons for increased incidence of this effect.

The main strength of this study is derived from the fact it is the first study of its kind from Iraq. Secondly, randomization ensured comparable groups. There are several limitations to our study. Success of ESWL is in- 
fluenced by the surgeon's skill. However, all ESWL was performed by same physician with good experience to reduce this discrepancy. Although follow up of the patient was done weekly, the exact time of stone expulsion was difficult to ascertain in some cases. Number of cases was not sufficient to control for confounding variables.

\section{Conclusion}

Adjunctive use of Tamsulosin in combination with ESWL was effective for reducing the time to stone expulsion in patient with 5 - $10 \mathrm{~mm}$ lower ureteric stone and reducing attack of pains, but had no significant improvement demonstrated in terms of stone free rate.

\section{References}

[1] Segura, J.W., Preminger, G.M., Assimos, D.G., Dretler, S.P., Kahn, R.I., Lingeman, J.E., et al. (1997) Ureteral Stones Clinical Guidelines Panel Summary Report on the Management of Ureteral Calculi. The Journal of Urology, 158, 1915-1921. http://dx.doi.org/10.1016/S0022-5347(01)64173-9

[2] Lam, J.S., Greene, T.D. and Gupta, M. (2002) Treatment of Proximal Ureteral Calculi:Holmium:YAG Laser Ureterolithotripsy versus Extracorporeal Shock Wave Lithotripsy. The Journal of Urology, 167, 1972-1976. http://dx.doi.org/10.1016/S0022-5347(05)65065-3

[3] Dellabella, M., Milanese, G. and Muzzonigro, G. (2003) Efficacy of Tamsulosin in the Medical Management of Juxtavesical Ureteral Stones. The Journal of Urology, 170, 2202-2205.

http://dx.doi.org/10.1097/01.ju.0000096050.22281.a7

[4] Dellabella, M., Milanese, G. and Muzzonigro, G. (2005) Randomized Trial of the Efficacy of Tamsulosin, Nifedipine and Phloroglucinol in Medical Expulsive Therapy for Distal Ureteral Calculi. The Journal of Urology, 174, 167-172. http://dx.doi.org/10.1097/01.ju.0000161600.54732.86

[5] Cervenakov, I., Fillo, J., Mardiak, J., Kopečnú, M., Šmirala, J. and Labaš, P. (2002) Speedy Elimination of Ureterolithiasis in Lower Part of Ureters with the Alpha 1-Blocker-Tamsulosin. International Urology and Nephrology, 34, 2529. http://dx.doi.org/10.1023/A:1021368325512

[6] Yilmaz, E., Batislam, E., Basar, M.M., Tuglu, D., Ferhat, M. and Basar, H. (2005) The Comparison and Efficacy of 3 Different $\alpha 1$-Adrenergic Blockers for Distal Ureteral Stones. The Journal of Urology, 173, 2010-2012. http://dx.doi.org/10.1097/01.ju.0000158453.60029.0a

[7] Küpeli, B., Irkilata, L., Gürocak, S., Tunç, L., Kiraç, M., Karaoğlan, Ü., et al. (2004) Does Tamsulosin Enhance Lower Ureteral Stone Clearance with or without Shock Wave Lithotripsy? Urology, 64, 1111-1115.

http://dx.doi.org/10.1016/j.urology.2004.07.020

[8] Hawker, G.A., Mian, S., Kendzerska, T. and French, M. (2011) Measures of Adult Pain: Visual Analog Scale for Pain (VAS Pain), Numeric Rating Scale for Pain (NRS Pain), Mcgill Pain Questionnaire (MPQ), Short-Form Mcgill Pain Questionnaire (SF-MPQ), Chronic Pain Grade Scale (CPGS), Short Form-36 Bodily Pain Scale (SF-36 BPS), and Measure of Intermittent and Constant Osteoarthritis Pain (ICOAP). Arthritis Care \& Research, 63, S240-S252. http://dx.doi.org/10.1016/j.urology.2004.07.020

[9] Kobayashi, M., Naya, Y., Kino, M., Awa, Y., Nagata, M., Suzuki, H., et al. (2008) Low Dose Tamsulosin for Stone Expulsion after Extracorporeal Shock Wave Lithotripsy: Efficacy in Japanese Male Patients with Ureteral Stone. International Journal of Urology, 15, 495-498. http://dx.doi.org/10.1111/j.1442-2042.2008.02033.x

[10] Resim, S., Ekerbicer, H.C. and Ciftci, A. (2005) Role of Tamsulosin in Treatment of Patients with Steinstrasse Developing after Extracorporeal Shock Wave Lithotripsy. Urology, 66, 945-948. http://dx.doi.org/10.1016/j.urology.2005.05.029

[11] Falahatkar, S., Khosropanah, I., Vajary, A.D., Bateni, Z.H., Khosropanah, D. and Allahkhah, A. (2011) Is There a Role for Tamsulosin after Shock Wave Lithotripsy in the Treatment of Renal and Ureteral Calculi? Journal of Endourology, 25, 495-498. http://dx.doi.org/10.1089/end.2010.0439

[12] Wang, H.J., Liu, K., Ji, Z.G. and Li, H.Z. (2010) Effect of $\alpha_{1}$-Adrenergic Antagonists on Lower Ureteral Stones with Extracorporeal Shock Wave Lithotripsy. Asian Journal of Surgery, 33, 37-41. http://dx.doi.org/10.1016/S1015-9584(10)60007-3

[13] Gravas, S., Tzortzis, V., Karatzas, A., Oeconomou, A. and Melekos, M. (2007) The Use of Tamsulozin as Adjunctive Treatment after ESWL in Patients with Distal Ureteral Stone: Do We Really Need It? Urological Research, 35, 231235. http://dx.doi.org/10.1007/s00240-007-0106-4

[14] Richardson, C.D., Donatucci, C.F., Page, S.O., Wilson, K.H. and Schwinn, D.A. (1997) Pharmacology of Tamsulosin: Saturation-Binding Isotherms and Competition Analysis Using Cloned $\alpha_{1}$-Adrenergic Receptor Subtypes. The Prostate, 33, 55-59. http://dx.doi.org/10.1002/(SICI)1097-0045(19970915)33:1<55::AID-PROS9>3.0.CO;2-8 
[15] Roehrborn, C., Van Kerrebroeck, P. and Nordling, J. (2003) Safety and Efficacy of Alfuzosin 10 mg Once-Daily in the Treatment of Lower Urinary Tract Symptoms and Clinical Benign Prostatic Hyperplasia: A Pooled Analysis of Three Double-Blind, Placebo-Controlled Studies. BJU international, 92, 257-261. http://dx.doi.org/10.1046/j.1464-410X.2003.04309.x

[16] Höfner, K. and Jonas, U. (2002) Alfuzosin: A Clinically Uroselective $\alpha_{1}$-Blocker. World Journal of Urology, 19, 405412. http://dx.doi.org/10.1007/s00345-002-0244-9

[17] Lepor, H. (1998) Phase III Multicenter Placebo-Controlled Study of Tamsulosin in Benign Prostatic Hyperplasia. Urology, 51, 892-900. http://dx.doi.org/10.1016/S0090-4295(98)00126-5

[18] Narayan, P. and Bruskewitz, R. (2000) A Comparison of Two Phase III Multicenter, Placebo-Controlled Studies of Tamsulosin in BPH. Advances in Therapy, 17, 287-300. http://dx.doi.org/10.1007/BF02850012

[19] Nasu, K., Moriyama, N., Fukasawa, R., Tsujimoto, G., Tanaka, T., Yano, J., et al. (1998) Quantification and Distribution of $\alpha_{1}$-Adrenoceptor Subtype mRNAs in Human Proximal Urethra. British Journal of Pharmacology, 123, 12891293. http://dx.doi.org/10.1038/sj.bjp.0701731

[20] Giuliano, F., Allard, F., McKenna, K., Jardin, A., Benoit, G. and Bernabe, J. (2002) Tamsulosin Has More Deleterious Effects than Alfuzosin on Parameters Characterizing Ejaculation in Anaesthetized Rats. International Journal of Impotence Research, 14, S12. 